\title{
Characterization of Cardiolipin as the Sodiated Ions by Positive-Ion Electrospray Ionization with Multiple Stage Quadrupole Ion-Trap Mass Spectrometry
}

\author{
Fong-Fu Hsu and John Turk \\ Mass Spectrometry Resource, Division of Endocrinology, Diabetes, Metabolism, and Lipid Research, \\ Department of Internal Medicine, Washington University School of Medicine, St. Louis, Missouri, USA
}

\begin{abstract}
The application of multiple-stage ion-trap (IT) mass spectrometric methods for the structural characterization of cardiolipin (CL), a 1,3-bisphosphatidyl-sn-glycerol that consists of four fatty acyl chains and three glycerol backbones (designated as A, B, and central glycerol, respectively), as the sodiated adduct ions in the positive-ion mode was evaluated. Following collisionally activated dissociation (CAD), the $[\mathrm{M}-2 \mathrm{H}+3 \mathrm{Na}]^{+}$ions of CL yield two prominent fragment ion pairs that consist of the phosphatidyl moieties attached to the $1^{\prime}$ - and $3^{\prime}$-position of the central glycerol, respectively, resulting from the differential losses of the diacylglycerol moieties containing A and B glycerol, respectively. The results are consistent with those previously described for the $[\mathrm{M}-\mathrm{H}]^{-}$and $[\mathrm{M}-2 \mathrm{H}$ $+\mathrm{Na}]^{-}$ions in the negative-ion mode, thus permitting assignment of the two phosphatidyl moieties attached to the 1'- or 3'-position of the central glycerol. The identities of the fatty acyl substituents and their positions on the glycerol backbones (glycerol A and B) are deduced from further degradation of the above ion pairs that give the fragment ions reflecting the fatty acid substituents at the $s n-1$ (or $\left.s n-1^{\prime}\right)$ and $s n-2$ (or $\left.s n-2^{\prime}\right)$ positions. The ions that arise from losses of the fatty acid substituents at $s n-1$ and $s n-1^{\prime}$, respectively, are prominent, but the analogous ions from losses of the fatty acid substituents at $s n-2$ and $s n-2^{\prime}$, respectively, are of low abundance in the $\mathrm{MS}^{2}$ product-ion spectra. This feature further confirms the assignment of the positions of the fatty acid substituents. The similar IT multiple-stage mass spectrometric approaches including $\mathrm{MS}^{2}$ and $\mathrm{MS}^{3}$ for structural characterization of $\mathrm{CL}$ using its $[\mathrm{M}+\mathrm{Na}]^{+}$and the $[\mathrm{M}-\mathrm{H}+2 \mathrm{Na}]^{+}$ions are also readily applicable. However, their uses for structural characterization are less desirable because formation of the $[\mathrm{M}+\mathrm{Na}]^{+}$and the $[\mathrm{M}-\mathrm{H}+2 \mathrm{Na}]^{+}$ions for $\mathrm{CL}$ is not predictable. (J Am Soc Mass Spectrom 2006, 17, 1146-1157) (c 2006 American Society for Mass Spectrometry
\end{abstract}

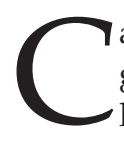
ardiolipin (CL) (I) is a 1,3-bisphosphatidyl-snglycerol, which consists of a phosphatidylglycerol linked to a phosphoglyceride skeleton $[1,2]$. Because the molecular species of cardiolipin are complex due to the diversity of different chain lengths and the varying degrees of unsaturation for the fatty acid substituents, as well as due to the permutations of the four fatty acyl substituents that result in a large number of potential combinations, unraveling the structure of cardiolipin has been a very difficult task [3-5].

Published online June 5, 2006

Address reprint requests to Dr. F.-F. Hsu, Box 8127, Department of Internal Medicine, Washington University School of Medicine, 660 S. Euclid, St. Louis, MO 63110, USA. E-mail: fhsu@im.wustl.edu

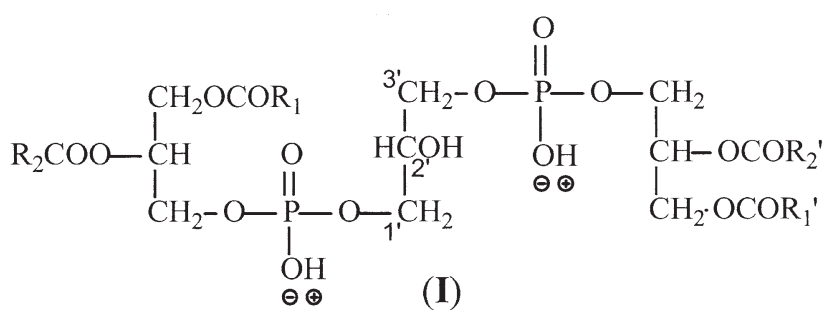

ESI with tandem mass spectrometry including tandem quadrupole [6], quadrupole time-of-flight (Q-TOF) [7], and ion-trap [8] instruments has emerged as a powerful tool in the characterization of cardiolipin and glucosylcardiolipin as the $[\mathrm{M}-\mathrm{H}]^{-}$and $[\mathrm{M}-2 \mathrm{H}+$ $\mathrm{Na}]^{-}$ions in the negative-ion mode, as well as the [M $2 \mathrm{H}+3 \mathrm{Na}]^{+}$ion in the positive-ion mode. The subclasses of cardiolipin of glucosyl-, alanyl-, and lysocardiolipins, also were previously characterized by FAB with sector mass spectrometer [9]. These methods are useful for identification of the fatty acyl substituents but 


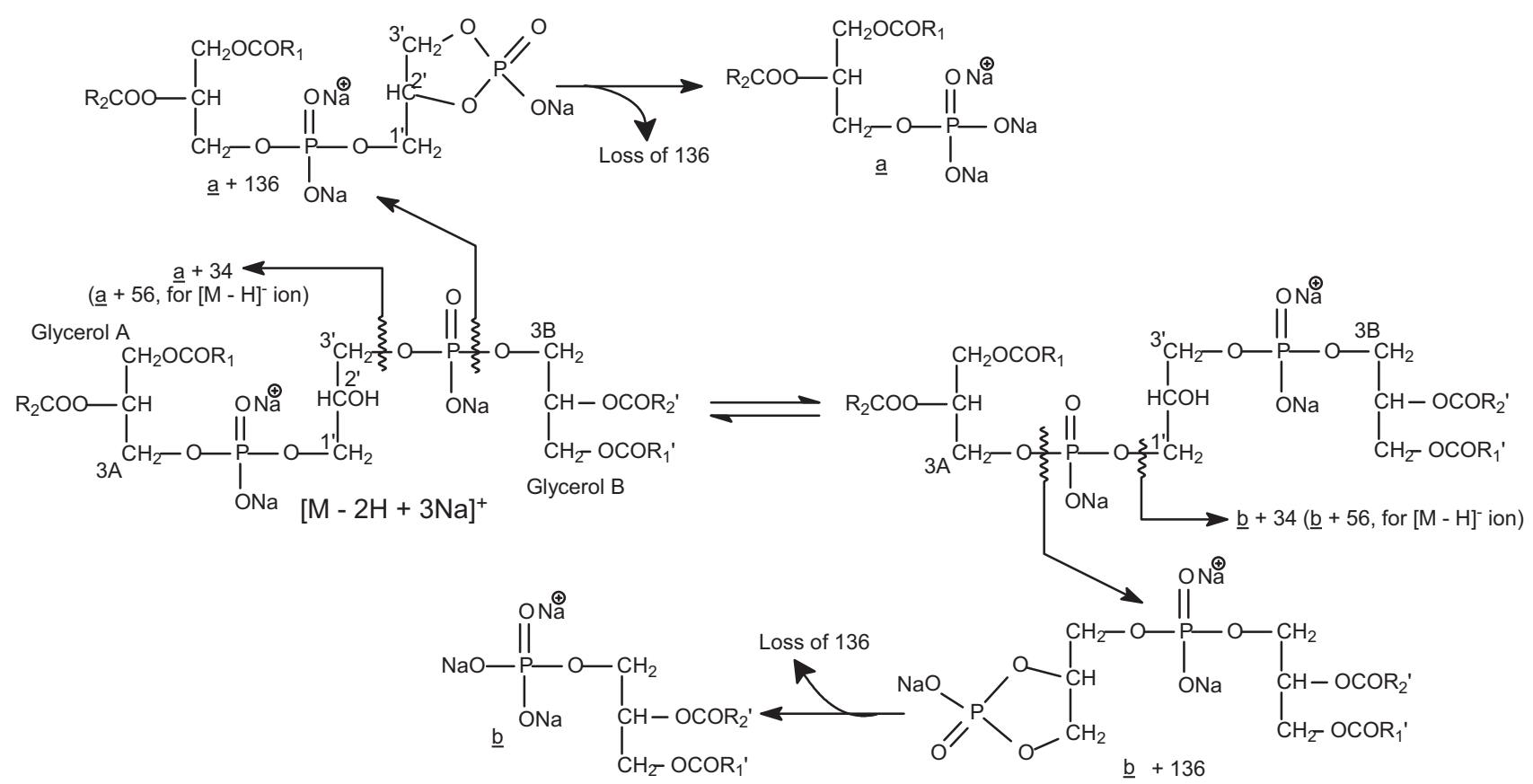

Scheme 1. The fragmentation processes proposed for formation of the $[a+136]$ (or $[b+136]),[a+$ $34]($ or $[b+34])$, and $[a]$ (or $[b]$ ) ions for the $[\mathrm{M}-2 \mathrm{H}+3 \mathrm{Na}]^{+}$ions of CL. The fragmentation pathways are consistent with those observed for the $[\mathrm{M}-\mathrm{H}]^{-}$and $[\mathrm{M}-2 \mathrm{H}+\mathrm{Na}]^{-}$ions.

are not useful for determination of their positions on the glycerol backbone.

Recently, we described the approaches using multiple-stage ion-trap mass spectrometric methods for the characterization of CLs as their $[\mathrm{M}-\mathrm{H}]^{-}[10]$ and $[\mathrm{M}-$ $2 \mathrm{H}+\mathrm{Na}]^{-}$ions [11] generated by ESI in the negativeion mode. The methods permit the structure of complex cardiolipins, including the identities of the fatty acyl substituents and their positions on the glycerol backbone to be unveiled in detail. In this report, we describe the positive-ion multiple-stage IT mass spectrometric approach for characterization of $\mathrm{CL}$ as the sodiated ions in the forms of $[\mathrm{M}-2 \mathrm{H}+3 \mathrm{Na}]^{+},[\mathrm{M}-\mathrm{H}+2 \mathrm{Na}]^{+}$, and $[\mathrm{M}+\mathrm{Na}]^{+}$.

\section{Materials}

Cardiolipins (received as disodium salts) isolated from E. coli were purchased from Avanti Polar Lipid (Alabaster, AL). All chemicals used in the analysis were purchased from Fisher Scientific (Pittsburgh, PA).

\section{Methods}

\section{Mass Spectrometry}

Low-energy CAD tandem mass spectrometry experiments were conducted on a Finnigan (San Jose, CA) LCQ DECA ion-trap mass spectrometer (ITMS) with the X-Calibur operating system. The methanolic CL mixture from E. coli $(10 \mathrm{pmol} / u \mathrm{~L})$ was continuously infused (3 $u \mathrm{~L} / \mathrm{min}$ ) to the ESI source, where the skimmer was set at ground potential, the electrospray needle was set at $4.5 \mathrm{kV}$, and temperature of the heated capillary was $260^{\circ} \mathrm{C}$. The automatic gain control of the ion trap was set to $5 \times 10^{7}$, with a maximum injection time of $400 \mathrm{~ms}$. Helium was used as the buffer and collision gas at a pressure of $1 \times 10^{-3}$ mbar. A enhanced resolution scan (defined as zoom scan by the vendor) was used to acquire the baseline resolved full-scan mass spectra. The $\mathrm{MS}^{\mathrm{n}}$ experiments were carried out with a relative collision energy ranged from 30 to $40 \%$ and with an activation q value at 0.25 . The activation time was set at $100 \mathrm{~ms}$. Mass spectra were accumulated in the profile mode, typically for 3-5 min for $\mathrm{MS}^{2}$ - and $\mathrm{MS}^{3}$-spectra. The mass resolution of the instrument was tuned to 0.6 $\mathrm{Da}$ at half peak height.

\section{Nomenclature}

To simplify data interpretation, we adopt the rules recommended by IUPAC with modification for designation of CL. Briefly, the three glycerol moieties are designated as A, B, and central glycerol (Scheme 1). The stereospecific numbering $(s n)$ of the $\mathrm{C} 1 \mathrm{~A}$ and $\mathrm{C} 2 \mathrm{~A}$ (A glycerol) carbons are designated as $s n-1$ and $s n-2$, respectively. The $\mathrm{C} 1 \mathrm{~B}$ and $\mathrm{C} 2 \mathrm{~B}$ (B glycerol) carbons are designated as $s n-1^{\prime}$ and $s n-2^{\prime}$, respectively. The carbon number of the central glycerol is designated as C-1', $\mathrm{C}-2^{\prime}$, and $\mathrm{C}-3^{\prime}$ with the $\mathrm{C}-1^{\prime}$ attached to the phosphatidic moiety with glycerol A. Abbreviation of cardiolipin, such as (16:0/16:1)(18:0/18:1)-CL signifies that the 16:0-, 16:1-, 18:0-, and 18:1-fatty acyl substituents attach to $\mathrm{C} 1 \mathrm{~A}, \mathrm{C} 2 \mathrm{~A}, \mathrm{C} 1 \mathrm{~B}$, and $\mathrm{C} 2 \mathrm{~B}$, respectively. The product- 


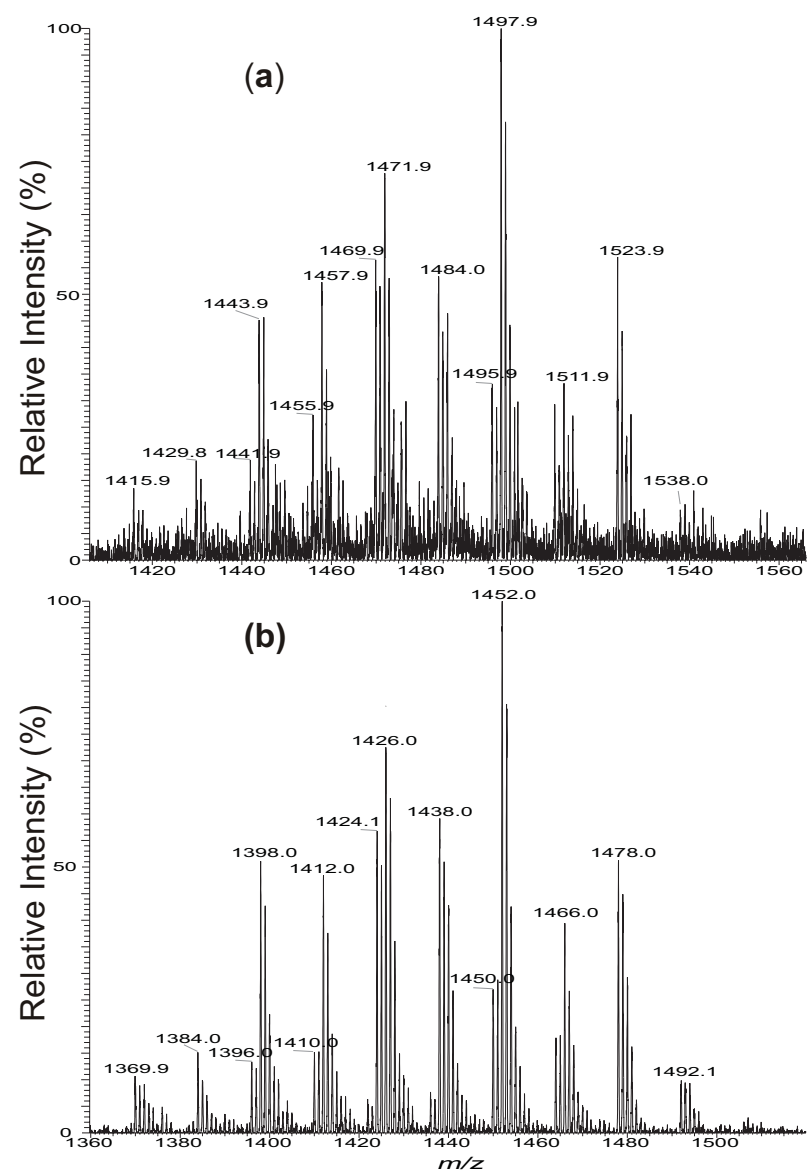

Figure 1. The zoom scan ESI/MS spectra of (a) the $[\mathrm{M}-2 \mathrm{H}+$ $3 \mathrm{Na}]^{+}$ions and (b) the $[\mathrm{M}-2 \mathrm{H}+\mathrm{Na}]^{-}$ions of the cardiolipin mixture isolated from $E$. coli.

ion spectra from $\mathrm{MS}^{n}(n=2,3,4)$ experiments are denoted as the $\mathrm{MS}^{\mathrm{n}}$-spectra $(n=2,3,4)$.

\section{Results and Discussion}

In the positive-ion mode, the methanolic solution of disodium salt of cardiolipin mixture, for example, from E. coli, forms mainly the $[\mathrm{M}-2 \mathrm{H}+3 \mathrm{Na}]^{+}$ions (Figure 1a), but the sensitivity is nearly one order less than that observed as the $[\mathrm{M}-2 \mathrm{H}+\mathrm{Na}]^{-}$ion in the negative-ion mode (Figure $1 \mathrm{~b}$ ). The profiles of the enhanced resolution ESI mass spectra of the $[\mathrm{M}-2 \mathrm{H}+3 \mathrm{Na}]^{+}$ions (Panel a) and the $[\mathrm{M}-2 \mathrm{H}+\mathrm{Na}]^{-}$ions (Panel b) are similar, and are also identical to that obtained as the [M $-\mathrm{H}]^{-}$ions from the same mixture in which $\mathrm{Na}^{+}$has been removed (data not shown). The ions in the forms of $[\mathrm{M}-\mathrm{H}+2 \mathrm{Na}]^{+}$and $[\mathrm{M}+\mathrm{Na}]^{+}$were observed in the positive-ion mode when $\mathrm{Na}^{+}$was not completely removed from the solution (data not shown). The characterization of cardiolipins as the sodiated adduct ions using multiple-stage IT mass spectrometry is described below.
The Fragmentation Processes of the $[\mathrm{M}-2 \mathrm{H}+3 \mathrm{Na}]^{+}$ ions of Cardiolipins

Similar to the major fragmentation processes that were previously reported for the $[\mathrm{M}-2 \mathrm{H}+\mathrm{Na}]^{-}$and $[\mathrm{M}-$ $\mathrm{H}]^{-}$ions of $\mathrm{CL}[10,11]$, the $[\mathrm{M}-2 \mathrm{H}+3 \mathrm{Na}]^{+}$ions of $\mathrm{CL}$ mainly undergo cleavages of the $\mathrm{C}(3 \mathrm{~B}) \mathrm{O}-\mathrm{P}$ and the $\mathrm{C}(3 \mathrm{~A}) \mathrm{O}-\mathrm{P}$ bonds, following resonance excitation in an ion-trap. As shown in Figure 2, the $\mathrm{MS}^{2}$-spectrum of the $[\mathrm{M}-2 \mathrm{H}+3 \mathrm{Na}]^{+}$ion of $(16: 0 / 18: 1)(16: 0 / 18: 1)-\mathrm{CL}$ at $\mathrm{m} / \mathrm{z}$ 1471.9 (Panel a) is dominated by the $(\underline{a}+136)$ and $(\underline{b}+$ 136) ions at $m / z 877$ (Scheme 1), analogous to the ion at $\mathrm{m} / \mathrm{z}$ 831 observed for the $[\mathrm{M}-2 \mathrm{H}+\mathrm{Na}]^{-}$ion at $\mathrm{m} / \mathrm{z} 1425.9$ (Panel b) [11]. The ion is also analogous to the $m / z 809$ ion observed for the $[\mathrm{M}-\mathrm{H}]^{-}$ion at $\mathrm{m} / z 1403$ (Panel c). However, the ion at $\mathrm{m} / \mathrm{z} 809$ gives rise to a prominent phosphatidic anion at $m / z 673$ (a and $\underline{b}$ ) by further loss of 136 [10]; while the analogous ion at $m / z 741(877-136)$ from consecutive loss of 136 is of low abundance in the MS $^{2}$-spectrum of $m / z 1471$ (Figure 2a). The ions at $m / z 775$ $([\underline{a}+34]$ and $[\underline{b}+34])$, arising from loss of a glycerophosphatidic acid as a sodium salt and analogous to the ion at $\mathrm{m} / \mathrm{z} 729$ observed for the $[\mathrm{M}-2 \mathrm{H}+\mathrm{Na}]^{-}$ion at $\mathrm{m} / \mathrm{z}$ 1425.9 (Figure 2b) [11] and the $[\mathrm{M}-\mathrm{H}]^{-}$ion at $\mathrm{m} / \mathrm{z} 1403$ (Figure 2c) [10] are also of low abundance.

In Figure 2a, the $m / z 1215$ (1471 - 256) ion reflecting loss of the 16:0-fatty acid substituent at $s n-1$ (or $s n-1^{\prime}$ ) is more abundant than the $\mathrm{m} / \mathrm{z} 1189$ (1471 - 282) ion, arising from loss of the 18:1-fatty acid substituent at $s n-2$ (or $\left.s n-2^{\prime}\right)$. The results indicate that the 18:1- and 16:0fatty acyl substituents are located at $s n-2\left(\right.$ or $\left.s n-2^{\prime}\right)$ and $s n-1$ (or $s n-1^{\prime}$ ) of the glycerol A (or B), respectively. This is in agreement with the notion that when the alkali adduct ions of glycerophospholipids were subjected to low-energy CAD in the positive-ion mode, the dissociation leading to loss of the fatty acid substituent at $s n-1$ is more facile than that at $s n-2$, because the $\alpha$-hydrogen of the fatty acyl substituent at $s n-2$ (or $s n-2^{\prime}$ ) that participates in the loss of $\mathrm{R}_{1} \mathrm{CO}_{2} \mathrm{H}$ (or $\left.\mathrm{R}_{1}, \mathrm{CO}_{2} \mathrm{H}\right)$ is more labile than that at $s n-1$ (or $s n-1^{\prime}$ ) [12-15]. This differential loss of the fatty acid substituents dependent on their position on the glycerol backbone provides a simple means for assignment of the position of the fatty acid substituents.

The major fragmentation processes that cleave the $\mathrm{C}(3 \mathrm{~B}) \mathrm{O}-\mathrm{P}$ and the $\mathrm{C}(3 \mathrm{~A}) \mathrm{O}-\mathrm{P}$ bonds are also seen for the ions that undergo primary loss of the fatty acid substituent. This is shown by the $\mathrm{MS}^{3}$-spectrum of the ion at $\mathrm{m} / \mathrm{z}$ 1215 (1471 $\rightarrow 1215$, Figure 2d), following loss of one of the 16:0-fatty acid substituent, as well as by the $\mathrm{MS}^{4}$-spectrum of the ion at $\mathrm{m} / \mathrm{z} 959(1471 \rightarrow 1215 \rightarrow 959$, Figure $2 \mathrm{e})$, following losses of the two 16:0-fatty acid substituents. The former spectrum (Figure 2d) shows the ion-pair at $\mathrm{m} / \mathrm{z}$ $877([\underline{a}+136]$ or $[\underline{b}+136]$ ion $)$ and $621([\underline{b}+136-$ $\left.\mathrm{C}_{15} \mathrm{H}_{31} \mathrm{CO}_{2} \mathrm{H}\right]$ or $\left[\underline{\mathrm{a}}+136-\mathrm{C}_{15} \mathrm{H}_{31} \mathrm{CO}_{2} \mathrm{H}\right]$ ion); while the latter spectrum (Figure 2e) is dominated by the ion at $\mathrm{m} / \mathrm{z}$ $621\left(\left[\underline{b}+136-\mathrm{C}_{15} \mathrm{H}_{31} \mathrm{CO}_{2} \mathrm{H}\right]\right.$ or $\left[\underline{a}+136-\mathrm{C}_{15} \mathrm{H}_{31} \mathrm{CO}_{2} \mathrm{H}\right]$ ion) (Scheme 2). In Figure $2 d$, the ions arising from loss of a glycerophosphatidic acid as the sodium salt are seen at 

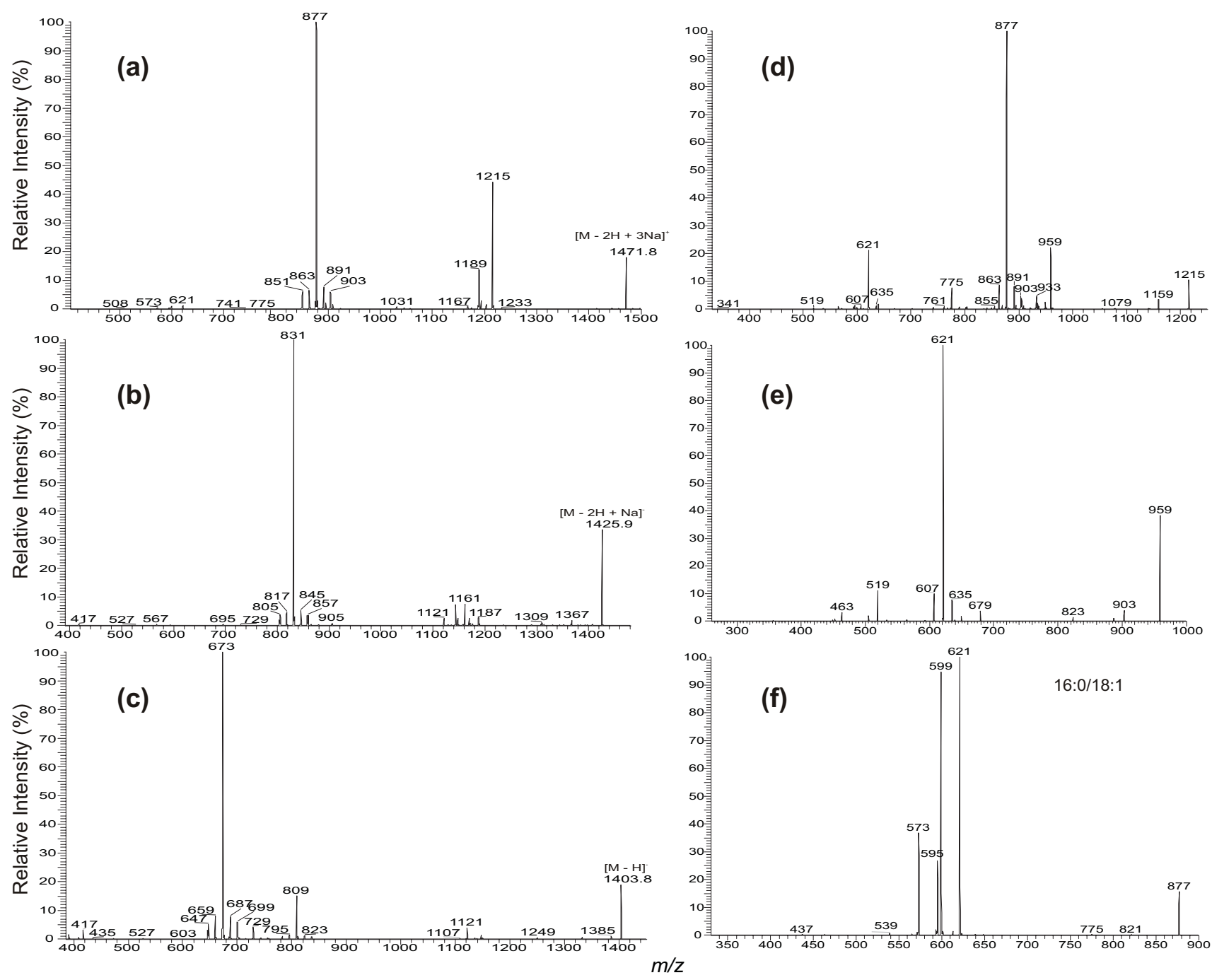

Figure 2. The IT $\mathrm{MS}^{2}$-spectra of $(16: 0 / 18: 1)(16: 0 / 18: 1)-\mathrm{CL}$ from (a) the $[\mathrm{M}-2 \mathrm{H}+3 \mathrm{Na}]^{+}$ion at $m / z$ $1471.9,(\mathbf{b})$ the $[\mathrm{M}-2 \mathrm{H}+\mathrm{Na}]^{-}$ion at $m / z 1425.9$, and $(\mathbf{c})$ the $[\mathrm{M}-\mathrm{H}]^{-}$ion at $\mathrm{m} / \mathrm{z} 1403.9$. The IT $\mathrm{MS}^{3}$-spectra of the $m / z 1215$ ion $(1471 \rightarrow 1215)(\mathbf{d})$, the IT MS ${ }^{4}$-spectrum of the $m / z$ 959 ion $(1471 \rightarrow 1215$ $\rightarrow$ 959) (e), and the IT MS ${ }^{3}$-spectrum of the $m / z 877$ ion $(1471 \rightarrow 877)(\mathbf{f})$ identify the phosphatidyl moieties. Ions at $m / z$ 850, 851, 903, 904 in (a), ions at $m / z$ 804, 805, 857, 858 in (b), and ions at $m / z$ 646, $647,699,700$ in (c) are from second isotopic contribution of the $m / z 1469.9\left([\mathrm{M}-2 \mathrm{H}+3 \mathrm{Na}]^{+}\right), 1423.9$ $\left([\mathrm{M}-2 \mathrm{H}+\mathrm{Na}]^{-}\right)$, and $1401.9\left([\mathrm{M}-\mathrm{H}]^{-}\right)$ions, respectively, which give the same nominal masses as the precursor ions.

$m / z 775([\underline{a}+34]$ or $[\underline{b}+34])$ and $519([\underline{b}+34]-$ $\mathrm{C}_{15} \mathrm{H}_{31} \mathrm{CO}_{2} \mathrm{H}$ or [a +34$\left.]-\mathrm{C}_{15} \mathrm{H}_{31} \mathrm{CO}_{2} \mathrm{H}\right)$. The ion at $\mathrm{m} / \mathrm{z}$ 959, arising from loss of the remaining 16:0-fatty acid substituent at $s n-1$ (or $s n-1^{\prime}$ ) is also more abundant than the ion at $\mathrm{m} / \mathrm{z} 933$ arising from loss of the 18:1-fatty acid substituent at $s n-2$ (or $s n-2^{\prime}$ ), consistent with the notion that loss of the fatty acid substituent at $s n-1$ (or $s n-1^{\prime}$ ) is more facile than that at $s n-2$ (or $\left.s n-2^{\prime}\right)$.

Further dissociation of the $\mathrm{m} / \mathrm{z} 877$ ion $(1471 \rightarrow 877$, Figure 2f) leads to the formation of the ions at $m / z 621$ and 599, arising from losses of 16:0-fatty acid substituent as an acid (loss of $\mathrm{C}_{15} \mathrm{H}_{31} \mathrm{CO}_{2} \mathrm{H}, 256 \mathrm{Da}$ ) and as a sodium salt (loss of $\mathrm{C}_{15} \mathrm{H}_{31} \mathrm{CO}_{2} \mathrm{Na}, 278 \mathrm{Da}$ ), respectively; while the ions at $\mathrm{m} / \mathrm{z} 595\left(877-\mathrm{C}_{17} \mathrm{H}_{33} \mathrm{CO}_{2} \mathrm{H}\right)$ and $573(877-$ $\mathrm{C}_{17} \mathrm{H}_{33} \mathrm{CO}_{2} \mathrm{Na}$ ) correspond to the analogous losses of the 18:1-fatty acid substituent. The ions at $\mathrm{m} / \mathrm{z} 621$ (877 $\left.\mathrm{C}_{15} \mathrm{H}_{31} \mathrm{CO}_{2} \mathrm{H}\right)$, and $599\left(877-\mathrm{C}_{15} \mathrm{H}_{31} \mathrm{CO}_{2} \mathrm{Na}\right)$ are, respectively, more abundant than the analogous ions at $\mathrm{m} / \mathrm{z} 595$ $\left(877-\mathrm{C}_{17} \mathrm{H}_{33} \mathrm{CO}_{2} \mathrm{H}\right)$, and $573\left(877-\mathrm{C}_{17} \mathrm{H}_{33} \mathrm{CO}_{2} \mathrm{Na}\right)$, indicating that the 16:0- and 18:1-fatty acyl substituents are located at $s n-1$ (or $s n-1^{\prime}$ ) and $s n-2$ (or $s n-2^{\prime}$ ) of the glycerol A (or B), respectively. The results, again, agree with the notion that loss of the fatty acid substituent at $s n-1$ is more favorable than that at $s n-2$, as described earlier. The structural assignment is also consistent with that deduced from the IT $\mathrm{MS}^{2}$ - and $\mathrm{MS}^{3}$-spectra of the $[\mathrm{M}-2 \mathrm{H}+\mathrm{Na}]^{-}$ ion at $\mathrm{m} / \mathrm{z} 1425$ [11], and of the $[\mathrm{M}-\mathrm{H}]^{-}$ion at $\mathrm{m} / \mathrm{z}$ 1403 [10].

In addition to the ions that arises from the $(18: 1 / 16$ : $0)(18: 1 / 16: 0)-C L$ isomer, the spectrum (Figure $2 a)$ also 


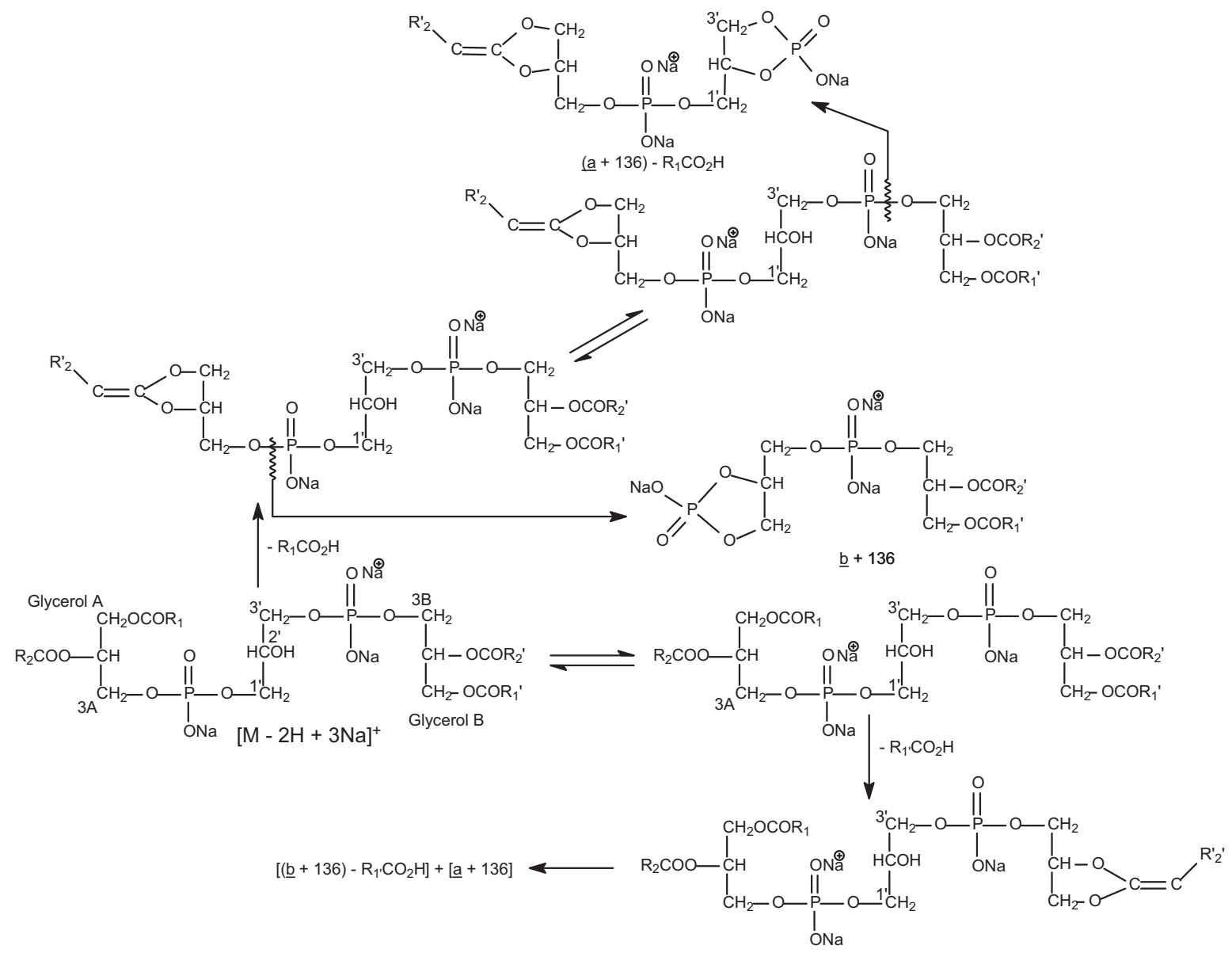

Scheme 2. The fragmentation pathways proposed for the $\left[\mathrm{M}-2 \mathrm{H}+3 \mathrm{Na}-\mathrm{R}_{(\text {or } 2)} \mathrm{CO}_{2} \mathrm{H}\right]^{+}$ions, arising from primary loss of the $\mathrm{R}_{1\left(\text { or } 1^{\prime}\right)} \mathrm{CO}_{2} \mathrm{H}$ substituent from the $[\mathrm{M}-2 \mathrm{H}+3 \mathrm{Na}]^{+}$ions of $\mathrm{CL}$.

contains another $(\underline{\mathrm{a}}+136)$ and $(\underline{\mathrm{b}}+136)$ ion pair at $\mathrm{m} / \mathrm{z}$ 891 and 863 , indicating the presence of an additional (16:0/19:1)(16:0/17:1)-CL structure. Structural characterization of the cardiolipin molecules consisting of multiple isomeric structures will be described later.

The IT MS ${ }^{2}$ product-ion spectrum of the $[\mathrm{M}-2 \mathrm{H}+$ $3 \mathrm{Na}]^{+}$ion at 1471.9 from $M$. bovis BCG [10] with a isomeric structure of $(18: 1 / 16: 0)(18: 1 / 16: 0)-C L$ also consists of a prominent ion at $m / z 877([\underline{a}+136]+[\underline{b}+136]$ ions) along with the ion at $\mathrm{m} / \mathrm{z} 1189(1471-282)$, arising from loss of the 18:1-fatty acid substituent at $s n-1$ (Figure 3a). The MS ${ }^{3}$ product-ion spectra of the ions at $m / z 1189(1471 \rightarrow 1189)$ (Figure $3 b$ ) and at $m / z 877$ (1471 $\rightarrow$ 877) (Figure 3c) contain ions analogous to those observed in Figure 2d and f, respectively, and clearly demonstrated that the 18:1- and 16:0-fatty acid substituents are located at $s n-1$ (or $\left.s n-1^{\prime}\right)$ and $s n-2$ (or $s n-2^{\prime}$ ), respectively.

\section{Structural Characterization of Cardiolipin Molecules Consisting of Two Various Phosphatidyl Moieties}

The formation of two distinct $(\underline{a}+136)$ and $(\underline{b}+136)$ ions by the cleavages of the $\mathrm{C}(3 \mathrm{~B}) \mathrm{O}-\mathrm{P}$ and the
$\mathrm{C}(3 \mathrm{~A}) \mathrm{O}-\mathrm{P}$ bonds, respectively, is seen in the $\mathrm{MS}^{2}$ spectra of the $[\mathrm{M}-2 \mathrm{H}+3 \mathrm{Na}]^{+}$ions of cardiolipins that consist of two various phosphatidyl moieties. As illustrated in Figure $4 \mathrm{a}$, the product-ion spectrum from $\mathrm{MS}^{2}$ of the $[\mathrm{M}-2 \mathrm{H}+3 \mathrm{Na}]^{+}$ion at $\mathrm{m} / \mathrm{z} 1495.9$ is dominated by the ion at $m / z 903(\underline{\mathbf{a}}+136)$, which is more abundant than another prominent ion at $m / z 875(\underline{b}+136)$. The results are similar to those observed for the corresponding $[\mathrm{M}-2 \mathrm{H}+\mathrm{Na}]^{-}$ion at $m / z 1449.9$, which shows a higher abundance of the $\mathrm{m} / \mathrm{z} 857$ (a ion) ion than the $\mathrm{m} / \mathrm{z}$ 829 (b ion) ion [11], and are consistent with the notion that CL contains two chemically distinct phosphatidyl moieties $[2,5,16,17]$ that may be liberated by the differential cleavage of the $\mathrm{C}(3 \mathrm{~A}) \mathrm{O}-\mathrm{P}$ and $\mathrm{C}(3 \mathrm{~B}) \mathrm{O}-\mathrm{P}$ bonds upon CAD. The finding that the $(\underline{a}+136)$ ion is more abundant than the $(\underline{b}+136)$ ion may indicate that the two ions correspond to the phosphatidyl moieties containing glycerol A and glycerol B, respectively $[10,11]$.

In the $\mathrm{MS}^{3}$-spectrum of the $\mathrm{m} / \mathrm{z} 875$ ion $(1495 \rightarrow 875)$ (Figure $4 b)$, the $m / z 593\left(875-\mathrm{C}_{17} \mathrm{H}_{33} \mathrm{CO}_{2} \mathrm{H}\right)$ and 571 $\left(875-\mathrm{C}_{17} \mathrm{H}_{33} \mathrm{CO}_{2} \mathrm{Na}\right)$ ions arising from further losses of the 18:1-fatty acyl substituent as an acid and as a sodium salt, respectively, are respectively more abundant than the ions at $m / z 621\left(875-\mathrm{C}_{15} \mathrm{H}_{29} \mathrm{CO}_{2} \mathrm{H}\right)$ and 

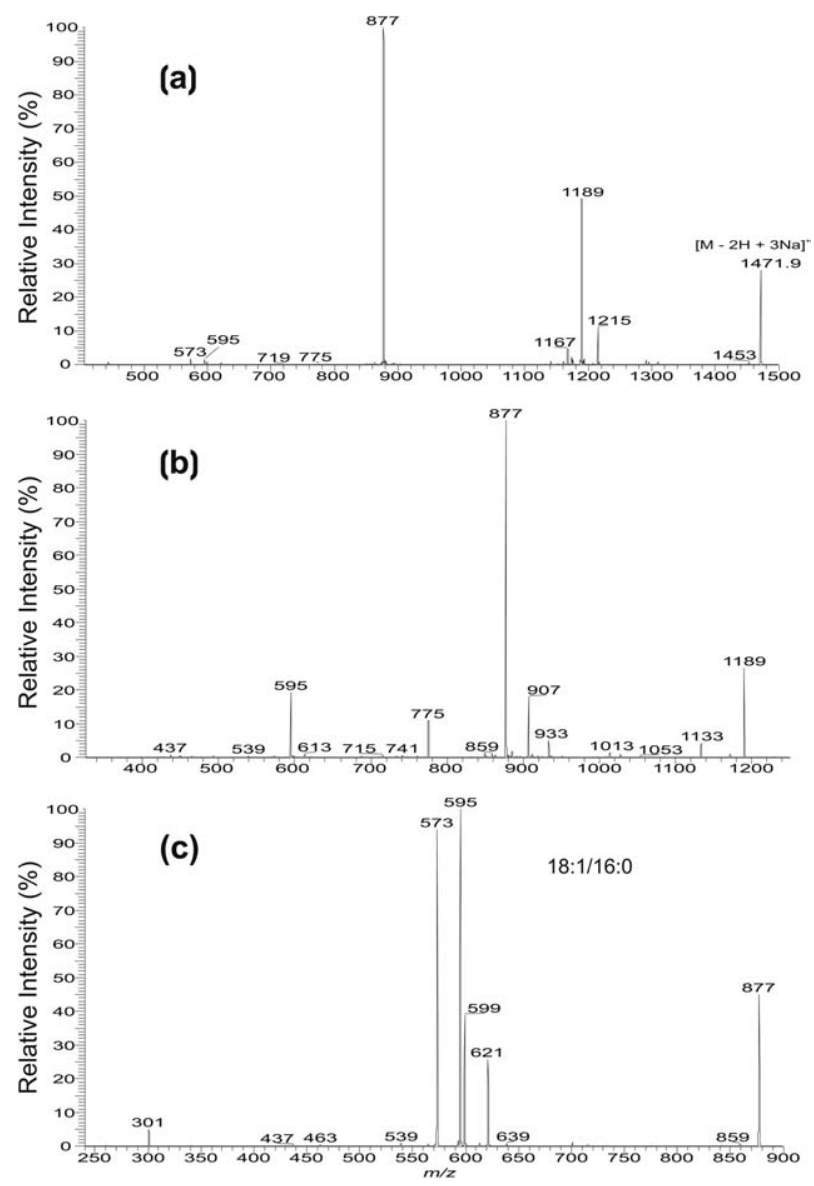

Figure 3. The IT $\mathrm{MS}^{2}$-spectra of (a) the $[\mathrm{M}-2 \mathrm{H}+3 \mathrm{Na}]^{+}$ion at $\mathrm{m} / \mathrm{z} 1471.9$, and the IT $\mathrm{MS}^{3}$-spectra of $(\mathbf{b})$ the $\mathrm{m} / \mathrm{z} 1189(1471 \rightarrow$ $1189)$ and (c) the $m / z 977(1471 \rightarrow 877)$ ions from the $(18: 1 / 16: 0)(18$ : 1/16:0)-CL isomer isolated from Mycobacterium bovis BCG. The spectra are in contrast with those observed in Figure 2 that arise from a $(16: 0 / 18: 1)(16: 0 / 18: 1)-C L$ isomer.

$599\left(875-\mathrm{C}_{15} \mathrm{H}_{29} \mathrm{CO}_{2} \mathrm{Na}\right)$ arising from the analogous losses of the 16:1-fatty acyl substituent, suggesting that the 18:1- and 16:1-fatty acyl moieties reside at $s n-1^{\prime}$ and $s n-2^{\prime}$ of glycerol B, respectively. The $\mathrm{MS}^{3}$-spectrum of the $m / z 903$ ion $(1495 \rightarrow 903)$ (Figure $4 \mathrm{c}$ ) is dominated by the ions at $m / z 621\left(903-\mathrm{C}_{17} \mathrm{H}_{33} \mathrm{CO}_{2} \mathrm{H}\right)$ and 599 (903 $\mathrm{C}_{17} \mathrm{H}_{33} \mathrm{CO}_{2} \mathrm{Na}$ ), arising from losses of the 18:1-fatty acyl substituent as an acid and as a sodium salt, respectively, indicating that the $\mathrm{m} / \mathrm{z} 903$ ion consists of a 18:1/18:1structure. The above results demonstrate that the $\mathrm{m} / \mathrm{z}$ 1495 ion is a $(18: 1 / 18: 1)(18: 1 / 16: 1)-C L$. This structural assignment is also consistent with the presence of a prominent ion at $m / z 1213$, arising from loss of the fatty acid substituent at $s n-1$ (or $s n-1^{\prime}$ ); while the ion at $\mathrm{m} / \mathrm{z}$ 1241 from loss of the 16:1-fatty acid at $s n-2^{\prime}$ is of low abundance (Figure 4a). The structural assignment is also in agreement with the fact that the ion at $\mathrm{m} / \mathrm{z} 931$ $(1213$ - 282) arising from further loss of the 18:1-fatty acid substituent at $s n-1$ (or $s n-1^{\prime}$ ) is more abundant than the ion at $\mathrm{m} / \mathrm{z} 959$ arising from further loss of the 16:1-fatty acid substituent at $s n-2^{\prime}$ in the $\mathrm{MS}^{3}$ mass spectrum of the $m / z 1213$ ion $(1495 \rightarrow 1213$ ) (Figure $4 d$ ).
The observation of the abundant ion pairs of $\mathrm{m} / \mathrm{z}$ 875/621 and 903/593 in Figure $4 d$ is also consistent with the notion that the 18:1-fatty acid substituent at $s n-1$ (or $s n-1^{\prime}$ ) was first cleaved from the ion at $m / z 1495$, followed by cleavages of the $\mathrm{C}(3 \mathrm{~B}) \mathrm{O}-\mathrm{P}$ and the $\mathrm{C}(3 \mathrm{~A}) \mathrm{O}-\mathrm{P}$ bonds, respectively. The IT MS ${ }^{4}$-spectrum of the $m / z 931$ ion $(1495 \rightarrow 1213 \rightarrow 931)$ (data not shown) arising from consecutive losses of the 18:1-fatty acid substituents at $s n-1$ and $s n-1^{\prime}$ is also dominated by ions at $m / z 621$ (903 - 282) and $593(875-282)$, further supporting the pathways that cleave the $\mathrm{C}(3 \mathrm{~B}) \mathrm{O}-\mathrm{P}$ and the $\mathrm{C}(3 \mathrm{~A}) \mathrm{O}-\mathrm{P}$ bonds.

In Figure $4 \mathrm{a}$, an ion at $m / z$ 889, representing both a $(\underline{b}+136)$ and a $(\underline{a}+136)$ ions is also present. The $\mathrm{MS}^{3}$-spectrum of $\mathrm{m} / \mathrm{z} 889(1495 \rightarrow 889)$ (shown later in Figure 5d) contains ions that are typical of an 18:1/17: 1 -structure. The results indicate that the $\mathrm{m} / \mathrm{z} 1495$ ion may also consist of a minor (18:1/17:1)(18:1/17:1)-CL structure. The $\mathrm{MS}^{3}$-spectrum of the $\mathrm{m} / \mathrm{z} 875$ ion (Figure $4 b)$ contains two minor peaks at $\mathrm{m} / \mathrm{z} 607$ and 585, corresponding to losses of the 17:1-fatty acid substituent as an acid and as a sodium salt, respectively, in addition to the major ions arising from the 18:1/16:1-structure that has been identified. The presence of the ions at $\mathrm{m} / \mathrm{z}$ 585 and 607 indicate that the $\mathrm{m} / \mathrm{z} 875$ ion may also consist of a minor 17:1/17:1-isomer and hence, the $\mathrm{m} / \mathrm{z}$ 1495 ion may also consist of a minor (18:1/18:1)(17:1/ 17:1)-CL species. Indeed, a minor ion at $\mathrm{m} / \mathrm{z} 1227$ (1495 - 268), corresponding to loss of a 17:1-fatty acid substituent is also present in the $\mathrm{MS}^{2}$-spectrum of $\mathrm{m} / \mathrm{z} 1495$ (Figure 4a). The characterization of the cardiolipin species consisting of multiple isomeric structures is described below.

\section{Characterization of Cardiolipin Molecules Consisting of Multiple Isomers}

More than one isomeric structures were identified for all the CL molecular species isolated from E. coli [11]. The characterization of the complex structures is exemplified by revealing the $\mathrm{m} / \mathrm{z} 1483.9$ ion in the mixture. The $\mathrm{MS}^{2}$-spectrum (Figure 5a) contains two prominent ions at $m / z 903(\underline{a}+136)$ and $863(\underline{b}+136)$ along with several sets of the ion pairs at $m / z 889(\underline{a}+136)$ and 877 $(\underline{b}+136)$, at $m / z 875(\underline{a}+136)$ and $891(\underline{b}+136)$, and at $m / z 849(\underline{a}+136)$ and $917(\underline{b}+136)$, consistent with those derived from the $[\mathrm{M}-\mathrm{H}]^{-}$ion at $\mathrm{m} / \mathrm{z} 1415.9$ (Figure $5 \mathrm{~b}$ ) and the $[\mathrm{M}-2 \mathrm{H}+\mathrm{Na}]^{-}$ion at $\mathrm{m} / z 1437.9$ (data not shown) in the negative-ion mode. The $\mathrm{MS}^{3}$ spectrum of the $m / z 903$ ion $(1483 \rightarrow 903)$ is identical to that shown in Figure 4c, which represents an 18:1/18: 1-structure. The $\mathrm{MS}^{3}$-spectrum of the $\mathrm{m} / \mathrm{z} 863$ ion (1483 $\rightarrow$ 863) (Figure 5c) represents a 16:0/17:1-structure, which is seen by a higher abundances of the ions at $\mathrm{m} / \mathrm{z}$ $607\left(863-\mathrm{C}_{15} \mathrm{H}_{31} \mathrm{CO}_{2} \mathrm{H}\right)$ and $585\left(863-\mathrm{C}_{15} \mathrm{H}_{31} \mathrm{CO}_{2} \mathrm{Na}\right)$, arising from losses of the 16:0-fatty acid substituent as an acid and as a sodium salt, respectively, than the ions at $\mathrm{m} / \mathrm{z} 595\left(863-\mathrm{C}_{16} \mathrm{H}_{31} \mathrm{CO}_{2} \mathrm{H}\right)$ and $573(863-$ 

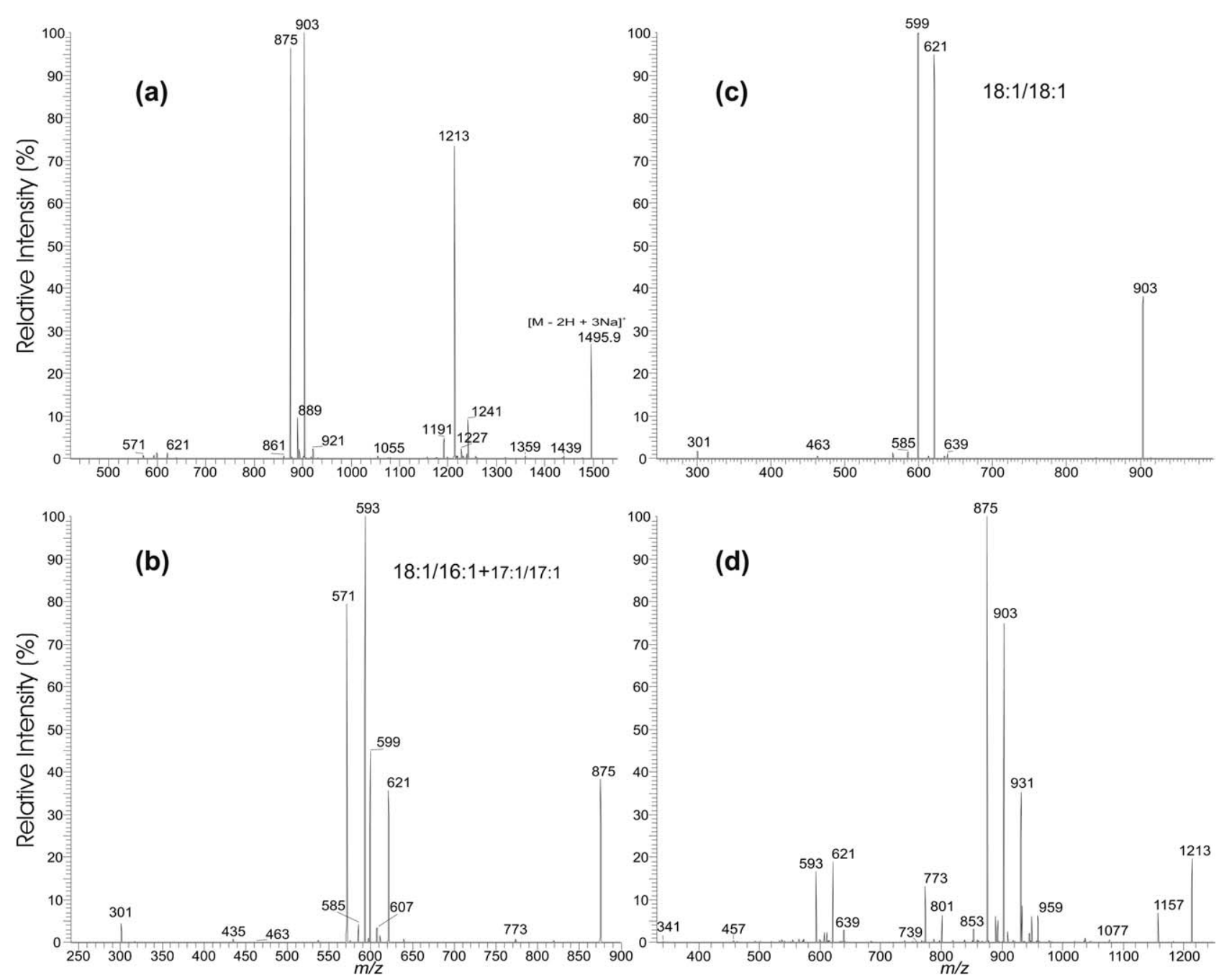

Figure 4. The IT $\mathrm{MS}^{2}$-spectrum of (a) the $[\mathrm{M}-2 \mathrm{H}+3 \mathrm{Na}]^{+}$ion at $\mathrm{m} / z 1495.9$, and the $\mathrm{MS}^{3}$-spectra of $(\mathbf{b})$ the $m / z 875$ ion $(1495 \rightarrow 875)$, (c) of the $m / z 903(1495 \rightarrow 903)$ ion, and (d) of the $m / z 1213$ ion (1495 $\rightarrow$ 1213). These spectra reveal a major (18:1/18:1)(18:1/16:1)-CL isomer and two minor (18:1/18:1)(17:

1/17:1)-CL and (18:1/17:1)(18:1/17:1)-CL structures.

$\mathrm{C}_{16} \mathrm{H}_{31} \mathrm{CO}_{2} \mathrm{Na}$ ), arising from the corresponding losses of the 17:1-fatty acid substituent. Therefore, a major species with a $(18: 1 / 18: 1)(16: 0 / 17: 1)-C L$ structure can be assigned.

The $\mathrm{MS}^{3}$-spectrum of the $\mathrm{m} / \mathrm{z} 877$ ion in the $\mathrm{m} / \mathrm{z}$ $889 / 877$ ion pair is identical to that shown in Figure $2 \mathrm{f}$, which represents a 16:0/18:1-structure; while the $\mathrm{MS}^{3}$ spectrum of the $m / z 889$ ion $(1483 \rightarrow 889)$ (Figure $5 \mathrm{~d}$ ) mainly consists of a 18:1/17:1-structure, which is identified by the observation of a greater abundance of the ions at $m / z 607\left(889-\mathrm{C}_{17} \mathrm{H}_{33} \mathrm{CO}_{2} \mathrm{H}\right)$ and $585(889-$ $\mathrm{C}_{17} \mathrm{H}_{33} \mathrm{CO}_{2} \mathrm{Na}$ ) than the ions at $\mathrm{m} / z$ 621 (889 $\left.\mathrm{C}_{16} \mathrm{H}_{31} \mathrm{CO}_{2} \mathrm{H}\right)$ and $599\left(889-\mathrm{C}_{16} \mathrm{H}_{31} \mathrm{CO}_{2} \mathrm{Na}\right)$. The spectrum also contains another two sets of minor ion pairs at $\mathrm{m} / \mathrm{z} 593\left(889-\mathrm{C}_{18} \mathrm{H}_{35} \mathrm{CO}_{2} \mathrm{H}\right)$ and $571(889-$ $\mathrm{C}_{18} \mathrm{H}_{35} \mathrm{CO}_{2} \mathrm{Na}$ ) corresponding to the losses from the 19:1-fatty acid substituent and at $\mathrm{m} / \mathrm{z} 635$ (889 $\left.\mathrm{C}_{15} \mathrm{H}_{31} \mathrm{CO}_{2} \mathrm{H}\right)$ and $613\left(889-\mathrm{C}_{15} \mathrm{H}_{31} \mathrm{CO}_{2} \mathrm{Na}\right)$, corresponding to the analogous losses of the 16:1-fatty acid substituent, indicating the presence of an additional 19:1/16:1-isomer. These results indicate that the 889/ 877 ion pair arises from a major $(18: 1 / 17: 1)(16: 0 / 18$ : 1)-CL and a minor (19:1/16:1)(16:0/18:1)-CL. The $\mathrm{MS}^{3}$ spectra of the ions at $\mathrm{m} / \mathrm{z} 875(1483 \rightarrow 875)$ (same as Figure $4 b), 891$ (1483 $\rightarrow$ 891) (not shown), 849 (1483 $\rightarrow$ 849) (not shown), and $917(1483 \rightarrow 917)$ (not shown) contain ions reflecting an 18:1/16:1-, 16:0/19:1-, 16:0/ $16: 1-$, and an 18:1/19:1-configurations, respectively. Because the $m / z 875$ ion is more abundant than the $m / z 891$ ion in the $875 / 891$ set, the CL with a $(18: 1 / 16: 1)(16: 0 /$ 19:1)-CL structure can be assigned, while the $849 / 917$ ion set may arise from a $(16: 0 / 16: 1)(18: 1 / 19: 1)-C L$ structure.

The above structural assignments are further supported by the $\mathrm{MS}^{3}$-spectrum of the $\mathrm{m} / \mathrm{z} 1201$ ion $(1483 \rightarrow$ 1201) (Figure 5e), which contains a prominent ion at $\mathrm{m} / \mathrm{z}$ 863, along with ions at $\mathrm{m} / \mathrm{z} 877,891$, and 849 . The presence of these ions is in agreement with the fact that the ion at $\mathrm{m} / \mathrm{z} 1483$ consists of a major $(18: 1 / 18: 1)(16: 0 /$ 17:1)-CL component along with the $(18: 1 / 17: 1)(16: 0 / 18$ : 

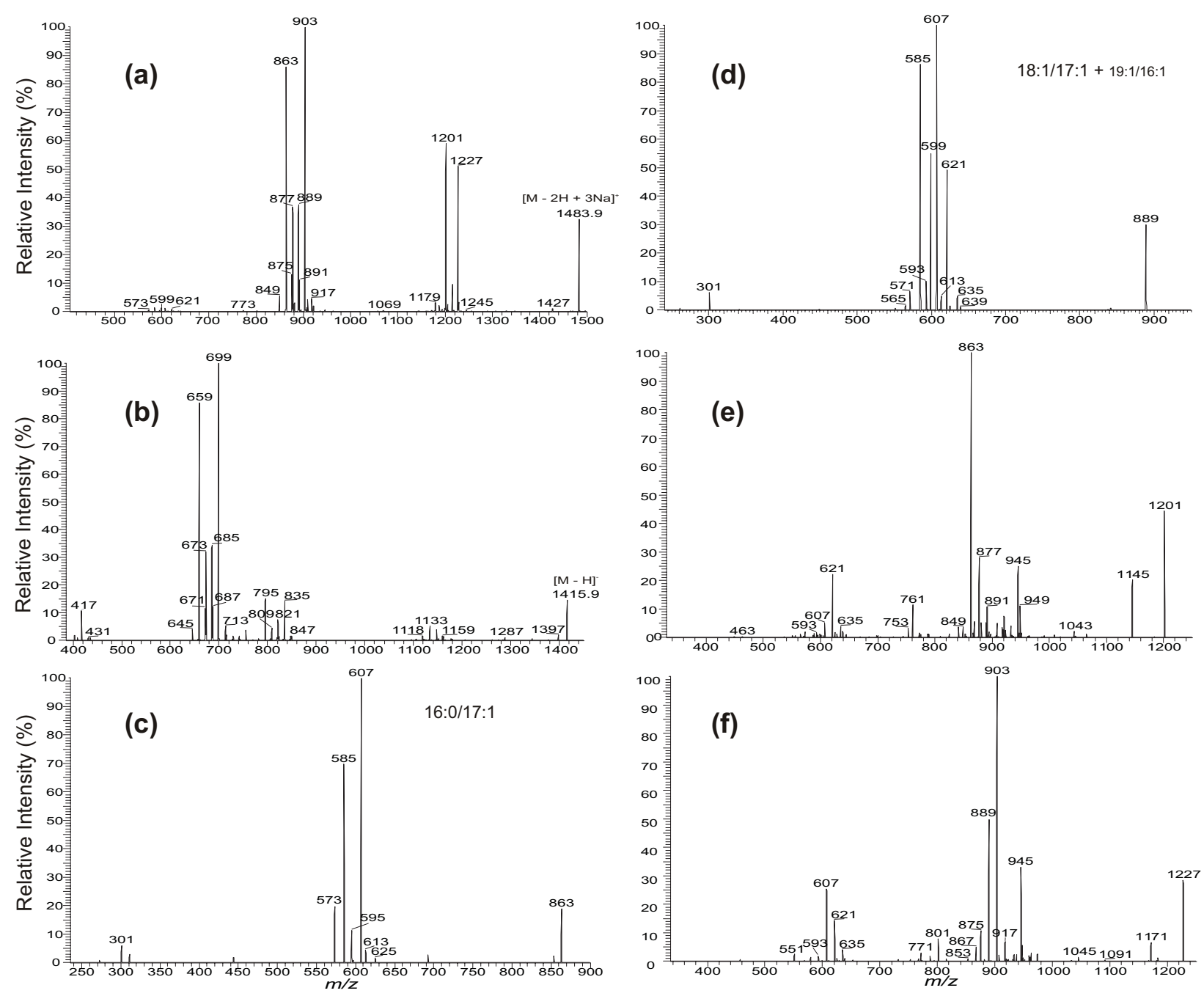

Figure 5. The IT $\mathrm{MS}^{2}$-spectra of (a) the $[\mathrm{M}-2 \mathrm{H}+3 \mathrm{Na}]^{+}$ion at $m / z 1483.9$, (b) the $[\mathrm{M}-\mathrm{H}]^{-}$ion at $m / z 1415.9$, and the IT MS ${ }^{3}$-spectra of the ions at $m / z 863(1483 \rightarrow 863)(\mathbf{c})$, at $m / z 889(1483 \rightarrow 889)($ d), at $m / z 1201(1483 \rightarrow 1201)(\mathbf{e})$, and at $m / z 1227(1483 \rightarrow 1227)(\mathbf{f})$. These combined structural information identified the (18:1/18:1)(16:0/17:1)-CL, (18:1/17:1)(16:0/18:1)-CL, (18:1/16:1)(16:0/19:1)-CL, and (18: 1/19:1)(16:0/16:1)-CL species. Because the $m / z 889$ ion also represent a minor 19:1/16:1 species (Figure 4d), a minor component with a (19:1/16:1)(16:0/18:1)-CL (or (16:0/18:1)(19:1/16:1)-CL) structure can also exist.

1)-CL, (18:1/16:1)(16:0/19:1)-CL, and (16:0/16:1)(18:1/ 19:1)-CL species. Upon CAD, ions from these species undergo preferential losses of the 18:1-fatty acid substituent at $s n-1$ (or $s n-1^{\prime}$ ) to yield a variety of the ions at $m / z$ 1201, which undergo further cleavages of the $\mathrm{C}(3 \mathrm{~A}) \mathrm{O}-\mathrm{P}$ bonds to form a major ion at $\mathrm{m} / \mathrm{z} 863$ along with ions at $m / z 877,891$, and 849 from the various isomers; while the ions at $\mathrm{m} / \mathrm{z} 621,607,593$, and 635 arise from cleavages of the $\mathrm{C}(3 \mathrm{~B}) \mathrm{O}-\mathrm{P}$ bonds (Scheme 2). The $\mathrm{MS}^{3}$-spectrum of the $\mathrm{m} / \mathrm{z} 1227$ ion $(1483 \rightarrow 1227)$ (Figure 5f) also contains a prominent ion set at $\mathrm{m} / \mathrm{z}$ $903 / 607$, along with the ion pairs at $\mathrm{m} / \mathrm{z} 889 / 621$, $875 / 635$, and $917 / 593$, arising from consecutive cleavages of the $\mathrm{C}(3 \mathrm{~B}) \mathrm{O}-\mathrm{P}$ and $\mathrm{C}(3 \mathrm{~B}) \mathrm{O}-\mathrm{P}$ bonds, following primary losses of the 16:0-fatty acid substituents at $s n-1^{\prime}$. The relative intensities of the aforementioned ions in Figures $5 \mathrm{e}$ and $\mathrm{f}$ are also in good agreement with those observed in Figure 5a, further supporting the fragmentation processes and the structural assignment for the $m / z 1483$ ion.

Another example that reveals the complex structures of CL is illustrated by the $\mathrm{MS}^{2}$-spectrum of the $\mathrm{m} / \mathrm{z} 1469$ ion (Figure 6a), which contains three major sets of the $(\underline{a}+136) /(\underline{b}+136)$ ion pairs at $m / z 875 / 877,903 / 849$, and $889 / 863$. The former ion is more abundant than the latter in each set and, thus, the position of the phosphatidyl group attached to $1^{\prime}$ - or 3'-position of the central glycerol can be determined. The results are also in agreement with those observed for the $[\mathrm{M}-\mathrm{H}]^{-}$ion at $m / z 1401.9$ (data not shown) and the $\left[\mathrm{M}-2 \mathrm{H}+\mathrm{Na}^{-}\right.$ion at $\mathrm{m} / \mathrm{z} 1423.9$ (Figure $6 \mathrm{~b}$ ) in the negative-ion mode. The $\mathrm{MS}^{3}$-spectra of the $m / z 875,877,903,849,889$, and $m / z 863$ ions are identical to those observed earlier and represent 18:1/16: 1-, 16:0/18:1-, 18:1/18:1-, 16:0/16:1-, 18:1/17:1-, and 16:0/ 


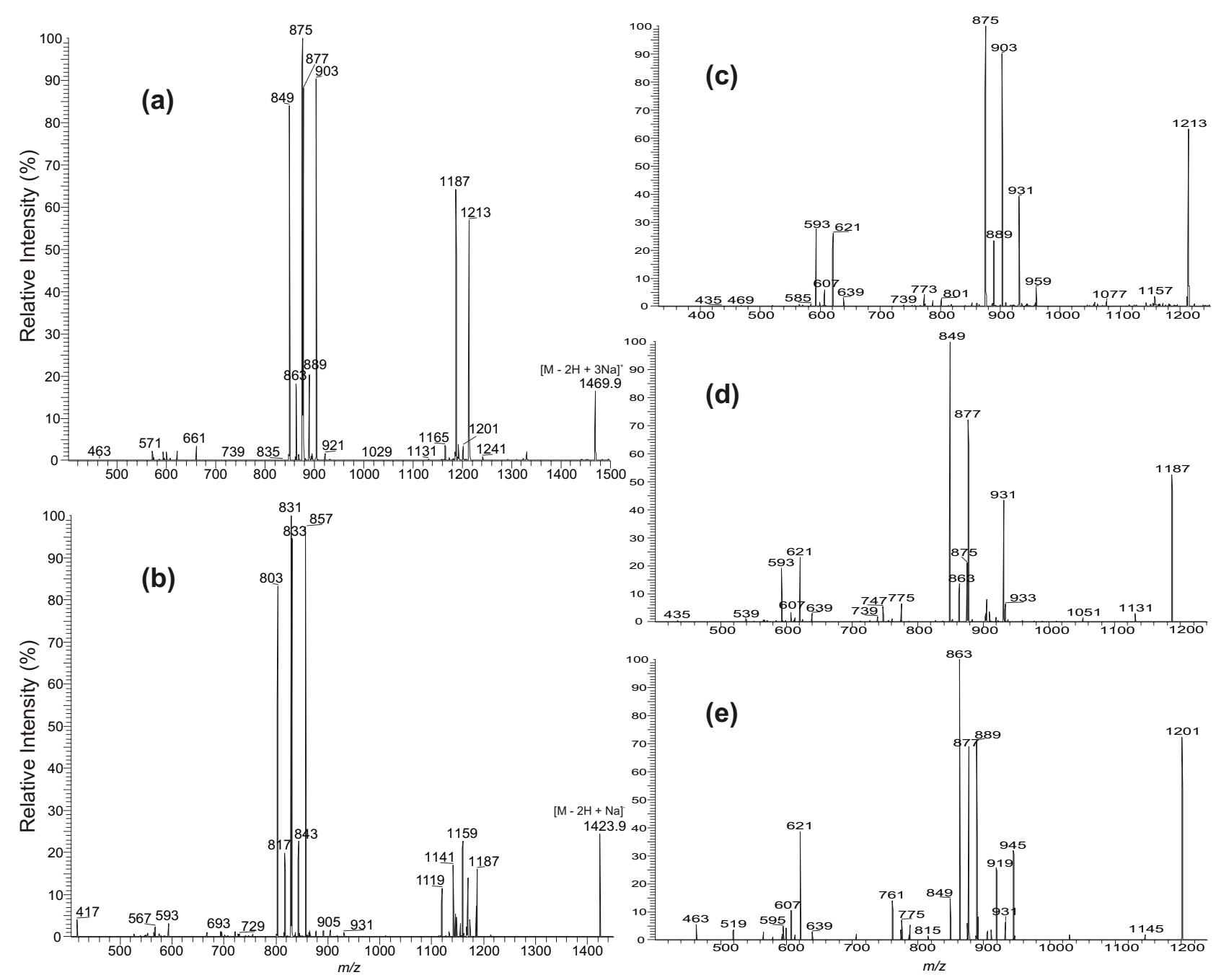

Figure 6. The IT $\mathrm{MS}^{2}$-spectra of (a) the $[\mathrm{M}-2 \mathrm{H}+3 \mathrm{Na}]^{+}$ion at $m / z 1469.9$ and (b) the $[\mathrm{M}-2 \mathrm{H}+$ $\mathrm{Na}]^{-}$ion at $m / z$ 1423.9. The consecutive fragmentations are shown in the $\mathrm{MS}^{3}$-spectra of (c) the $\mathrm{m} / \mathrm{z}$ 1213 ion $(1469 \rightarrow 1213)$, (d) the $m / z 1187$ ion $(1469 \rightarrow 1187)$, and $(\mathbf{e})$ of the $m / z 1201$ ion $(1469 \rightarrow 1201)$. The $m / z 1469$ ion (a) consists of two major (18:1/16:1)(16:0/18:1)-CL (from 875/877 pair) and (18:1/18:1)(16:0/16:1)-CL (from 903/849 pair) species, along with the minor (18:1/17:1)(16:0/17:1)-CL and (17:1/17:1) (16:0/18:1)-CL species (from 889/863 pair), consistent with those observed in (b), in which the analogous ion pairs are also seen. Only the major structure in each pair is shown. For example, the $m / z 889$ ion consists of a major 18:1/17:1- and minor 19:1/16:1-structures and the $m / z$ 849 ion consists of a major 16:0/16:1- and a minor 14:0/18:1-structures, but only the (18:1/17:1)(16:0/17: 1)-CL and (18:1/18:1)(16:0/16:1)-CL structures are described.

17:1-structures, respectively. These results indicate that the $m / z 1469$ ion is a mixture consisting of $(18: 1 / 16: 1)(16$ : 0/18:1)-CL, (18:1/18:1)(16:0/16:1)-CL, and (18:1/17:1)(16: 0/17:1)-CL isomers. The presence of these isomeric structures is also consistent with the prominence of the ions at $m / z 1187(1469-282)$ and $1213(1469-256)$, arising from losses of the 18:1- and 16:0-fatty acyl substituents at sn-1 and $s n-1^{\prime}$, respectively, in the $\mathrm{MS}^{2}$ of $m / z 1469.9$ (Figure 6a). These structural assignments are further supported by the $\mathrm{MS}^{3}$-spectra of the ions at $\mathrm{m} / \mathrm{z} 1213(1469 \rightarrow 1213)$ (Figure 6c) and at $m / z 1187(1469 \rightarrow 1187)$ (Figure 6d). The former spectrum is dominated by the $(\underline{a}+136) /(\underline{b}+136)$ ion pairs at $m / z 903 / 593$ and $875 / 621$, arising from cleavages of the $\mathrm{C}(3 \mathrm{~B}) \mathrm{O}-\mathrm{P}$ and $\mathrm{C}(3 \mathrm{~A}) \mathrm{O}-\mathrm{P}$ bonds of the major $(18: 1 / 18: 1)(16: 0 / 16: 1)-C L$ and $(18: 1 / 16: 1)(16: 0 / 18: 1)-C L$ isomers, following primary loss of the 16:0-fatty acid substituent at $s n-1^{\prime}$. The ion-pair arising from the similar cleavages of the minor (18:1/17:1)(16:0/17:1)-CL isomer, following loss of the 16:0-fatty acid substituent is seen at $\mathrm{m} / \mathrm{z}$ 889/607. The $\mathrm{MS}^{3}$-spectrum of the $\mathrm{m} / \mathrm{z} 1187$ ion (Figure 6d) consists of the prominent ion pairs at $\mathrm{m} / \mathrm{z}$ $849 / 621$ and $877 / 593$, along with a minor ion pair at $\mathrm{m} / \mathrm{z}$ $863 / 607$. These ions, again, arise from cleavages of the $\mathrm{C}(3 \mathrm{~B}) \mathrm{O}-\mathrm{P}$ and $\mathrm{C}(3 \mathrm{~A}) \mathrm{O}-\mathrm{P}$ bonds from the $(18: 1 / 18: 1)(16$ : 0/16:1)-CL, (18:1/16:1)(16:0/18:1)-CL, and (18:1/17:1)(16: 0/17:1)-CL isomers, respectively, following primary loss of the 18:1-fatty acid substituent at $s n-1$.

As shown earlier (Figure $4 \mathrm{~b}$ ), the ion at $\mathrm{m} / \mathrm{z} 875$ represents both a 18:1/16:1 and a 17:1/17:1 isomers. Therefore, the ion-pair at $\mathrm{m} / \mathrm{z} 875 / 877$ may also arise 


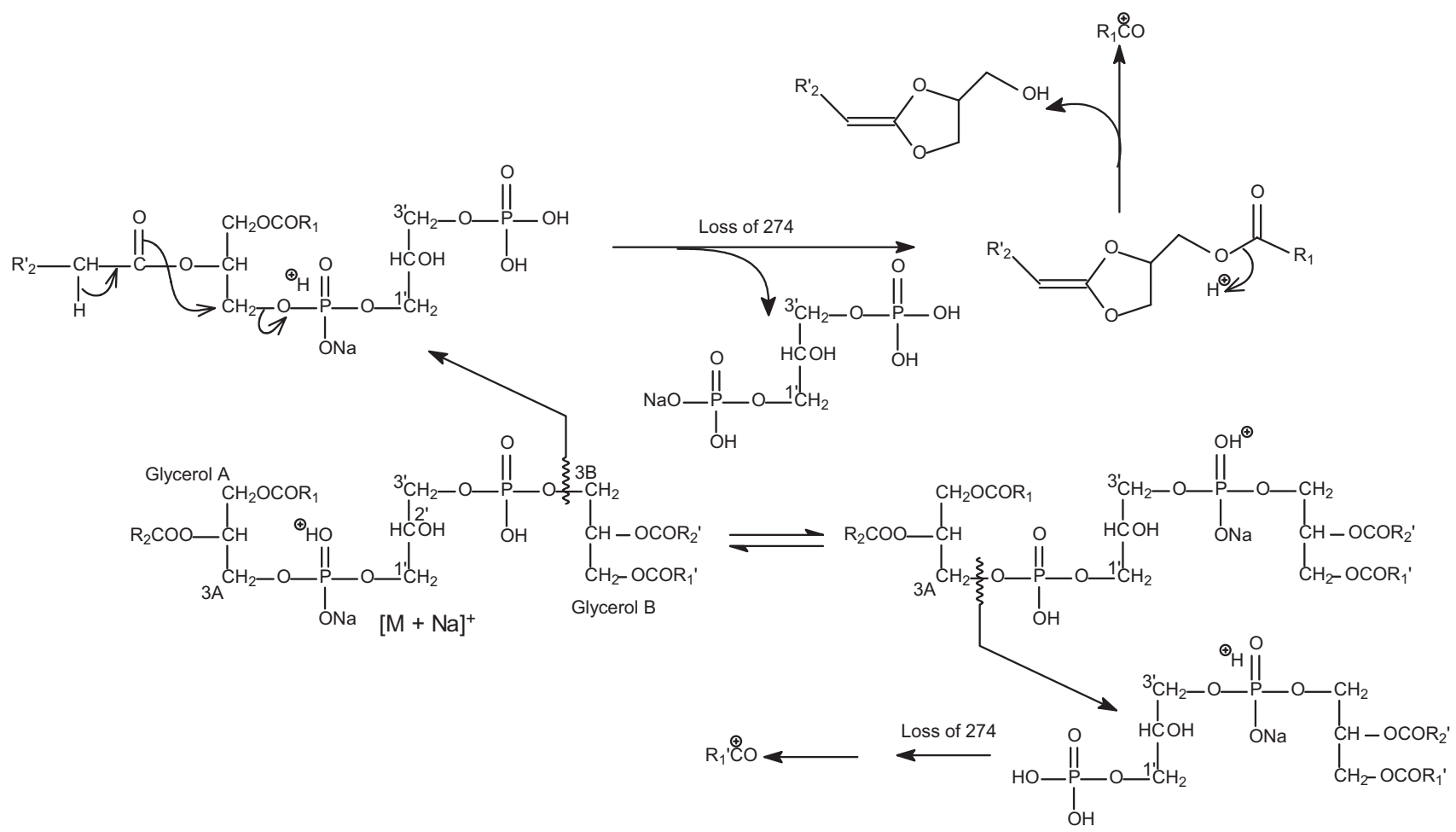

Scheme 3. The fragmentation pathways proposed for the $[\mathrm{M}+\mathrm{Na}]^{+}$ion of CL. Similar pathways were also observed for the $[\mathrm{M}-\mathrm{H}+2 \mathrm{Na}]^{+}$ion.

from a minor (17:1/17:1)(16:0/18:1)-CL (or a (16:0/18:1) (17:1/17:1)-CL) species. Indeed, both the ions at $\mathrm{m} / \mathrm{z} 877$ and 607 , arising from further cleavages of the $\mathrm{C}(3 \mathrm{~B}) \mathrm{O}-\mathrm{P}$ and $\mathrm{C}(3 \mathrm{~A}) \mathrm{O}-\mathrm{P}$ bonds are also present in the $\mathrm{MS}^{3}-$ spectrum of the minor ion at $\mathrm{m} / \mathrm{z} 1201(1469 \rightarrow 1201)$ (Figure 6e), arising from primary loss of a 17:1-fatty acid substituent. The spectrum also contains the ion-pairs at $\mathrm{m} / \mathrm{z} 863 / 621,889 / 595$, arising from further cleavages of the $\mathrm{C}(3 \mathrm{~B}) \mathrm{O}-\mathrm{P}$ and $\mathrm{C}(3 \mathrm{~A}) \mathrm{O}-\mathrm{P}$ bonds, following primary loss of the 17:1-fatty acid substituent at $s n-2$ from the (18:1/17:1)(16:0/17:1)-CL isomer. The ions at $m / z 945$ and 919, arising from losses of the 16:0- and 18:1-fatty acid substituents, respectively, are abundant; while the ion at $m / z$ 931, arising from further loss of a 17:1-fatty acid substituent is of low abundance. These results agree with the earlier findings that the ion at $\mathrm{m} / \mathrm{z} 1201$ also arises from a (18:1/17:1)(16:0/17:1)-CL isomer by loss of the 17:1-fatty acid substituent at $s n-2$ (or $s n-2^{\prime}$ ).

\section{Characterization of Cardiolipin as the $[\mathrm{M}+\mathrm{Na}]^{+}$ and $[\mathrm{M}-\mathrm{H}+2 \mathrm{Na}]^{+}$Ions}

Interestingly, the major fragmentation processes for the $[\mathrm{M}+\mathrm{Na}]^{+}$and $[\mathrm{M}-\mathrm{H}+2 \mathrm{Na}]^{+}$ions upon CAD arise from cleavages of the $\mathrm{C}(3 \mathrm{~B})-\mathrm{OP}$ and $\mathrm{C}(3 \mathrm{~A})-\mathrm{OP}$ bonds rather than the $\mathrm{C}(3 \mathrm{~B}) \mathrm{O}-\mathrm{P}$ and $\mathrm{C}(3 \mathrm{~A}) \mathrm{O}-\mathrm{P}$ bonds (Scheme 3), probably due to the presence of the acidic hydrogen that protonates the molecule of CL. The ion pairs arising from the cleavages are seen at $\mathrm{m} / \mathrm{z} 877$ and 851 , for the $[\mathrm{M}+\mathrm{Na}]^{+}$ion of $(18: 1 / 18: 1)(16: 0 / 18: 1)-\mathrm{CL}$ at $\mathrm{m} / \mathrm{z} 1453.9$ (Figure $7 \mathrm{a}$ ), which also yields the ions at $m / z 859\left(877-\mathrm{H}_{2} \mathrm{O}\right)$ and $833\left(851-\mathrm{H}_{2} \mathrm{O}\right)$ via further loss of a water molecule. The analogous ions from the similar cleavages were observed at $\mathrm{m} / \mathrm{z} 899,873,881$ $\left(889-\mathrm{H}_{2} \mathrm{O}\right)$, and $855\left(873-\mathrm{H}_{2} \mathrm{O}\right)$ for the $[\mathrm{M}-\mathrm{H}+$ $2 \mathrm{Na}]^{+}$adduct ion of $(18: 1 / 18: 1)(16: 0 / 18: 1)-C L$ at $\mathrm{m} / \mathrm{z}$ 1475.9 (Figure 7b). Again, the abundances of the former ions in each pair are greater than those of the latter ions, respectively, indicating that the former ions correspond to the phosphatidyl moieties containing glycerol A and the latter ions correspond to the phosphatidylglycerol moieties that contain glycerol $\mathrm{B}$. The results are consistent with those observed for the $[\mathrm{M}-\mathrm{H}]^{-}$and $[\mathrm{M}-2 \mathrm{H}$ $+\mathrm{Na}]^{-}$ions $[10,11]$. The assignments of the fatty acid substituents at the glycerol backbone are determined by further dissociation of the ion pairs.

The $\mathrm{MS}^{3}$-spectrum of the $\mathrm{m} / \mathrm{z} 851$ ion (data not shown) is dominated by the ion at $m / z 577$, reflecting loss of a sodium glycerol-1,3-diphosphate moiety (Scheme 3), and the spectrum is not sufficient for structural identification. However, further dissociation of the ion at $m / z 577(1453 \rightarrow 851 \rightarrow 577)$ (Figure 7c) gives the ion at $m / z 321$, reflecting loss of the 16:0-fatty acid substituent at $s n-1$. In contrast, the ion expected at $\mathrm{m} / \mathrm{z} 295$ arising from loss of the 18:1-fatty acid substituent at $s n-2$ is absent. The spectrum also contains a prominent ion at $\mathrm{m} / \mathrm{z} 265$, corresponding to a 18:1-fatty acyl cation, which is more abundant than the ion at $\mathrm{m} / \mathrm{z}$ 239, corresponding to a 16:0-fatty acyl cation. The results indicate that the 16:0- and 18:1-fatty acyl sub- 

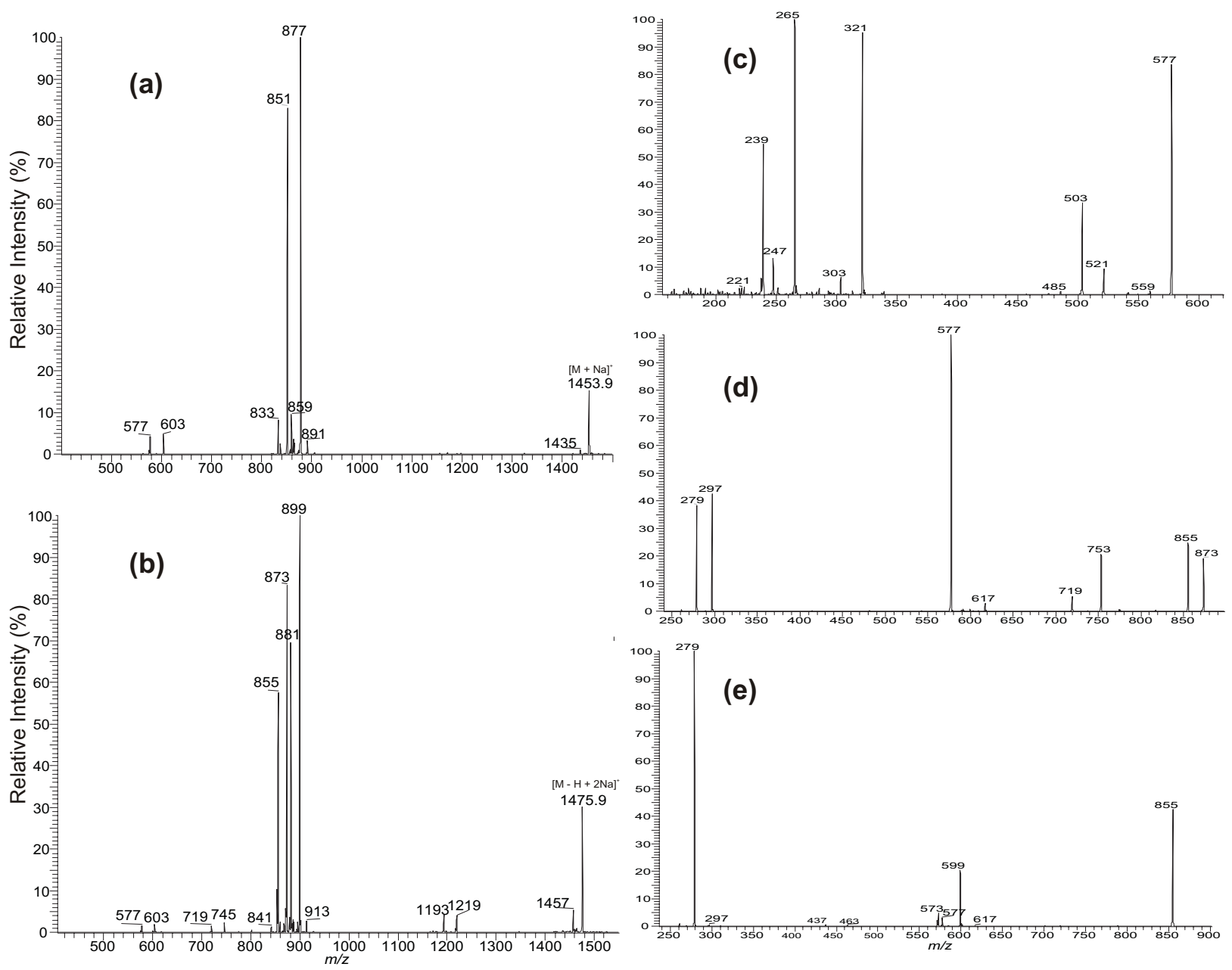

Figure 7. The IT MS ${ }^{2}$-spectra of (a) the $[\mathrm{M}+\mathrm{Na}]^{+}$ion at $\mathrm{m} / z 1453.9$ and $(\mathbf{b})$ of the $[\mathrm{M}-\mathrm{H}+2 \mathrm{Na}]^{+}$ ion at $m / z$ 1475.9. (c) The MS ${ }^{4}$-spectra of the $m / z 577$ ion $(1453 \rightarrow 851 \rightarrow 577)$. (d) The MS ${ }^{3}$-spectra of the $m / z 873$ ion $(1475 \rightarrow 873)$, and $(\mathbf{e})$ of the $m / z 855$ ion $(1475 \rightarrow 855)$. The combined spectral information indicates that ions at $m / z 1453$ and 1475 arise from (18:1/18:1)(16:0/18:1)-CL; while (c), (d), and (e) arise from a 16:0/18:1-structure.

stituents are located at $s n-1$ and $s n-2$, respectively [13]; whereas the analogous ion at $\mathrm{m} / \mathrm{z} 603$ arising from further dissociation of the ion at $\mathrm{m} / \mathrm{z} 877$ is composed of a 18:1/18:1-structure (data not shown). Therefore, a $(18: 1 / 18: 1)(16: 0 / 18: 1)-C L$ structure can be assigned.

The MS ${ }^{3}$-spectra of the ions at $m / z 873(1475 \rightarrow 873)$ (Figure $7 \mathrm{~d}$ ) and at $\mathrm{m} / \mathrm{z} 899$ (data not shown) are also dominated by the ions at $m / z 577$ and 603, respectively, and the spectra also do not provide the information regarding to the identities and the positions of the fatty acid substituents. However, further degradation of the ions at $\mathrm{m} / \mathrm{z} 577$ and 601 gives the identical spectra as described earlier (Figure 7c), consistent with the presence of a $(18: 1 / 18: 1)(16: 0 / 18: 1)-C L$. The MS $^{3}$-spectrum of the ion at $\mathrm{m} / \mathrm{z} 855(1475 \rightarrow 855)$ contains the ion at $\mathrm{m} / \mathrm{z}$ 599 , arising from loss of a 16:0-fatty acid substituent. The ion is more abundant than the ion at $\mathrm{m} / \mathrm{z} 573$, corresponding to loss of a 18:1-fatty acid substituent, indicating that the $\mathrm{m} / \mathrm{z} 855$ ion contains a 16:0/18:1structure; while the $\mathrm{MS}^{3}$-spectrum of the ion at $\mathrm{m} / \mathrm{z} 881$ leads to the assignment of a 18:1/18:1-structure. The combined information confirms that the $[\mathrm{M}-\mathrm{H}+$ $2 \mathrm{Na}^{+}$ion at $m / z 1475$ is a $(18: 1 / 18: 1)(16: 0 / 18: 1)-C L$, identical to that deduced from the $[\mathrm{M}+\mathrm{Na}]^{+}$ion at $\mathrm{m} / \mathrm{z}$ 1453.

\section{Conclusions}

The structural assignments of $C L$ and its fragmentation processes from the $[\mathrm{M}-2 \mathrm{H}+3 \mathrm{Na}]^{+}$ions are consistent with those derived from the $[\mathrm{M}-2 \mathrm{H}+\mathrm{Na}]^{-}$and $[\mathrm{M}-\mathrm{H}]^{-}$ions $[10,11]$. The feature that the ions reflecting the losses of the fatty acid substituents at $s n-1$ and $s n-1^{\prime}$ \{i.e., the $\left([\mathrm{M}-2 \mathrm{H}+3 \mathrm{Na}]^{+}-\mathrm{R}_{1} \mathrm{CO}_{2} \mathrm{H}\right)$ and the $\left([\mathrm{M}-2 \mathrm{H}+3 \mathrm{Na}]^{+}-\mathrm{R}_{1}, \mathrm{CO}_{2} \mathrm{H}\right)$ ions $\}$ are prominent as seen in the $\mathrm{MS}^{2}$-spectra, as well as the structural information deduced from the $\mathrm{MS}^{3}$-spectra of the $(\underline{a}+136)$ ion and the $(\underline{b}+136)$ ions, along with those obtained from the $\mathrm{MS}^{3}$-spectra of the $\left([\mathrm{M}-2 \mathrm{H}+3 \mathrm{Na}]^{+}\right.$$\left.\mathrm{R}_{1} \mathrm{CO}_{2} \mathrm{H}\right)$ and the $\left([\mathrm{M}-2 \mathrm{H}+3 \mathrm{Na}]^{+}-\mathrm{R}_{1}, \mathrm{CO}_{2} \mathrm{H}\right)$ ions 
readily permit confident assignments of complex CL structures. Because the $[\mathrm{M}-2 \mathrm{H}+3 \mathrm{Na}]^{+}$ions of $\mathrm{CL}$ is readily formed from its methanolic solution of the disodium salts upon desorption by ESI, characterization of $\mathrm{CL}$ as a $[\mathrm{M}-2 \mathrm{H}+3 \mathrm{Na}]^{+}$adduct ion in the positive-ion mode may be an alternative for its structural identification.

Although the IT multiple-stage mass spectrometric approaches for structural characterization using the [M $+\mathrm{Na}^{+}$and the $[\mathrm{M}-\mathrm{H}+2 \mathrm{Na}]^{+}$ions of CL can be achieved, the formation of the mono- and the disodiated CL species, nevertheless, is not predictable. In addition, fragment ions informative for assignments of the fatty acid substituents relied on the spectra from $\mathrm{MS}^{4}$ experiments that result in a drastic decline in sensitivity. Hence, the approaches for structural characterization are not very useful.

\section{Acknowledgments}

This research was supported by U.S. Public Health Service grants P41-RR-00,954， R37-DK-34,388， P60-DK-20,579， P01-HL-57,278, P30-DK-56,341, and a grant (996003) from the Juvenile Diabetes Foundation.

\section{References}

1. LeCocq J.; Ballou, C. E. On the Structure of Cardiolipin. Biochemistry 1964, 155, 976-980.

2. Powell, G. L.; Jacobus, J. The Nonequivalence of the Phosphorus Atoms in Cardiolipin. Biochemistry 1974, 13, 4024-4026.

3. Schlame, M.; Brody, S.; Hostetler, K. Y. Mitochondrial Cardiolipin in Diverse Eukaryotes. Comparison of Biosynthetic Reactions and Molecular Acyl Species. Eur. J. Biochem. 1993, 212, 727-735.

4. Schlame, M.; Otten, D. Analysis of Cardiolipin Molecular Species by High-Performance Liquid Chromatography of Its Derivative 1,3Bisphosphatidyl-2-Benzoyl-sn-Glycerol Dimethyl Ester. Anal. Biochem. 1991, 195, 290-295.
5. Schlame, M.; Ren, M.; Xu, Y.; Greenberg, M. L.; Haller, I. Molecular Symmetry in Mitochondrial Cardiolipins. Chem. Phys. Lipids 2005, 138, 38-49.

6. Valianpour, F.; Wanders, R. J. A.; Barth, P. G.; Overmars, H.; van Gennip, A. H. Quantitative and Compositional Study of Cardiolipin in Platelets by Electrospray Ionization Mass Spectrometry: Application for the Identification of Barth Syndrome Patients. Clin. Chem. 2002, 48, 1390-1397.

7. Beckedorf, A. I.; Schaffer, C.; Messner, P.; Peter-Katalinic, J. Mapping and Sequencing of Cardiolipins from Geobacillus stearothermophilus NRS 2004/3a by Positive and Negative Ion Nano-ESI-QTOF-MS and MS/ MS. J. Mass Spectrom. 2002, 37, 1086-1094.

8. Lesnefsky, E. S.; Stoll, M. S. K.; Minkler, P. E.; Hoppel, C. L. Separation and Quantitation of Phospholipids and Lysophospholipids by HighPerformance Liquid Chromatography. Anal. Biochem. 2000, 285, 246254.

9. Peter-Katalinic, J.; Fischer, W. $\alpha$-D-Glucopyranosyl-, D-Alanyl-, and L-Lysylcardiolipin from Gram-Positive Bacteria: Analysis by Fast Bombardment Mass Spectrometry. J. Lipid Res. 1998, 39, 2286-2292.

10. Hsu, F.-F.; Turk, J.; Rhoades, E. R.; Russell, D. G.; Shi, Y.; Groisman, E. A. Structural Characterization of Cardiolipin by Tandem Quadrupole and Multiple-Stage Quadrupole Ion-Trap Mass Spectrometry with Electrospray Ionization. J. Am. Soc. Mass Spectrom. 2005, 16, 491-504.

11. Hsu, F.-F.; Turk, J. Structural Characterization of Cardiolipin from Escherichia coli by Electrospray Ionization with Multiple Stage Quadrupole Ion-Trap Mass Spectrometric Analysis of $[\mathrm{M}-2 \mathrm{H}+\mathrm{Na}]^{-}$Ions. J. Am. Soc. Mass Spectrom. 2006, 17, 420-429.

12. Hsu, F.-F.; Turk, J. Electrospray Ionization/Tandem Quadrupole Mass Spectrometric Studies on Phosphatidylcholines: The Fragmentation Processes. I. Am. Soc. Mass Spectrom. 2003, 14, 352-363.

13. Hsu, F.-F.; Turk, J. Structural Studies on Phosphatidylserine by Tandem Quadrupole and Multiple Stage Quadrupole Ion-Trap Mass Spectrometry with Electrospray Ionization. J. Am. Soc. Mass Spectrom. 2005, 16, 1510-1522.

14. Hsu, F.- F.; Turk, J. Structural Characterization of Triacylglycerols as Lithiated Adducts by Electrospray Ionization Mass Spectrometry Using Low-Energy Collisionally Activated Dissociation on a Triple Stage Quadrupole Instrument. J. Am. Soc. Mass Spectrom. 1999, 10, 587-99.

15. Hsu, F.-F.; Turk, J.; Electrospray Ionization with Low-Energy Collisionally Activated Dissociation Tandem Mass Spectrometry of Complex Lipids: Structural Characterization and Mechanisms of Fragmentation. In Modern Methods for Lipid Analysis by Liquid Chromatography/Mass Spectrometry; Byrdwell, W. C., Ed.; AOCS Publication: Champaign, IL, 2005; pp 61-178.

16. Henderson, T. O.; Glonek, T.; Myers, T. C. Phosphorus-31 Nuclear Magnetic Resonance Spectroscopy of Phospholipids. Biochemistry 1974, 13, 623-628.

17. Kates, M.; Syz, J. Y.; Gosser, D.; Haines, T. H. pH-Dissociation Characteristics of Cardiolipin and Its 2'-Deoxy Analog. Lipids 1993, 28, $877-$ 882. 